\title{
Blood Levels of the Heavy Metal, Lead, and Caries in Children Aged 24-72 Months: NHANES III
}

\author{
R. Constance Wiener ${ }^{a, b}$ D. Leann Long ${ }^{d}$ Richard J. Jurevic ${ }^{c}$ \\ Departments of ${ }^{a}$ Dental Practice and Rural Health, ${ }^{b}$ Epidemiology, School of Public Health, ${ }^{c}$ Diagnostic Sciences, \\ School of Dentistry, and ${ }^{\mathrm{d} B i o s t a t i s t i c s, ~ W e s t ~ V i r g i n i a ~ U n i v e r s i t y, ~ M o r g a n t o w n, ~ W . V a ., ~ U S A ~}$
}

\section{Key Words}

Blood lead levels · Caries · Heavy metal · NHANES III

\begin{abstract}
Lead remains a significant pollutant. It has acute toxic and chronic effects on many tissues and accumulates in teeth and bones. The researchers for this study investigated the association of blood lead levels with the extent/severity of caries as measured by the number of decayed/filled teeth of children aged 24-72 months using data from NHANES III (the Third National Health and Nutrition Examination Survey), accounting for the excess zero caries in the analysis and using less than $2 \mu \mathrm{g} / \mathrm{dl}$ as the reference blood lead level $(n=3,127)$. Zero-inflated negative binomial regression models indicated unadjusted extent/severity mean ratios of $1.79,1.88$ and 1.94 for the number of decayed/filled teeth in children whose blood lead levels were $2-5,5-10$ and $>10 \mu \mathrm{g} / \mathrm{dl}$, respectively, compared with children having $<2 \mu \mathrm{g} / \mathrm{dl}$ blood lead levels. The results did not attenuate when other variables were added to the model for the $5-10$ and $>10 \mu \mathrm{g} / \mathrm{dl}$ levels of exposure. The adjusted extent/severity mean ratios were 1.84 , 2.14 and 1.91, respectively, for the categories. This study indicated a strong association of blood lead levels with increasing numbers of carious teeth in children aged 24-72
\end{abstract}

months. These findings support other studies in an innovative analysis handling cases of children with no caries. The findings may inform caries risk assessment.

(c) 2014 S. Karger AG, Base

Environmental lead remains a public health concern. Lead exposure has been known to have health consequences for two millennia [Gilbert and Weiss, 2006]. Acute lead poisoning presents with abdominal distress, vomiting, neuropathies, myalgia, weakness, and confusion [Rosin, 2009]. Chronic lead exposure interferes with nerve conduction, enzymes that depend upon calcium, ATPases, oxidative phosphorylation in mitochondria, production of heme, the status of membranes, the metabolism of steroids, and sperm count [Rosin, 2009]. With chronic lead exposure, gingival changes can occur with the development of dark 'lead lines' [Rosin, 2009]. There is also concern of a relationship of increased bone lead levels and renal diseases, cataracts, hypertension, and degenerative dementia [Rosin, 2009].

In evaluating blood lead levels for lead exposure, the Centers for Disease Control and Prevention (CDC) used the 97th percentile of blood lead levels in US children in

\section{KARGER 125}

(c) 2014 S. Karger AG, Base

0008-6568/14/0491-0026\$39.50/0

E-Mail karger@karger.com

www.karger.com/cre
R. Constance Wiener, DMD, PhD

Dental Practice and Rural Health, School of Dentistry

Department of Epidemiology, School of Public Health, West Virginia University PO Box 9448 104A Health Sciences Center Addition Morgantown, WV 26506 (USA)

E-Mail rwiener2@hsc.wvu.edu 
two consecutive National Health and Nutrition Examination Survey (NHANES) cycles as the upper reference level for children aged 1-5 years [Wheeler and Brown, 2013]. From 2007 to 2010, 2.6\% of children (an estimated $535,000)$ had high blood lead levels $(\geq 5 \mu \mathrm{g} / \mathrm{dl})$ [Gilbert and Weiss, 2006]. Progress in decreasing childhood blood lead levels is occurring. The geometric mean blood lead level was $15 \mu \mathrm{g} / \mathrm{dl}$ from 1976 to $1980,3.6 \mu \mathrm{g} / \mathrm{dl}$ from 1988 to $1991,1.9 \mu \mathrm{g} / \mathrm{dl}$ from 1999 to 2002 , and $1.3 \mu \mathrm{g} / \mathrm{dl}$ from 2007 to 2010 [Wheeler and Brown, 2013]. However, the following argument has been made: (1) no blood level of lead is safe, particularly to the developing nervous system of children, (2) blood lead levels of $2 \mu \mathrm{g} / \mathrm{dl}$ are readily and accurately measurable and, therefore, (3) the upper blood lead level limit should be $2 \mu \mathrm{g} / \mathrm{dl}$ [Gilbert and Weiss, 2006].

The precipitous drop in lead exposure in children has been attributed to the ban on lead as a constituent of paint (which occurred In 1978), reducing lead in vehicle emissions, remediation of surfaces painted with lead-based paints, remediation of soil in play areas for children, reducing the marketing of products with lead to children, and awareness and monitoring of food such as rice [CDC, 2009; Jaslow, 2013; Wheeler and Brown, 2013]. A source of lead that may affect an unborn child is the maternal blood level of lead (which increases during pregnancy) and lead in breast milk from maternal lead exposure which may have occurred decades earlier [Watson et al., 1997]. Lead has a half-life of roughly 62 years in the body [Watson et al., 1997].

The evidence surrounding the link between lead exposure and dental caries has been reported in previous research motivated by the known accumulation of lead in bones and teeth [Martin et al., 2007; Alomary et al., 2013]. Heavy metals such as lead, cadmium and zinc are assimilated in enamel during mineralization as well as after eruption [Youravong et al., 2005, 2006; Alomary et al., 2013]. Lead has been reported to be able to incorporate into primary teeth from 4 months prenatally until the teeth naturally exfoliate [Gierat-Kucharzewska et al., 2003]. The proposed method is that lead, in its divalent cationic state, substitutes for isovalent calcium sites in dentinal hydroxyapatite [Alomary et al., 2013]. Several studies have attempted to identify tooth tissue concentration differences (enamel vs. dentin; crowns vs. roots) to identify both spatial and temporal deposition rates. Lead exposure and dental caries may have a temporal relationship in that antenatal and early exposure may result in teeth being more vulnerable to caries development. Whereas adults absorb $10 \%$ of a dose of lead, chil-

Blood Levels of Lead and Caries: Children Aged 24-72 Months dren absorb $40 \%$ and retain $30 \%$ while adults retain $1 \%$ [Rosin, 2009]. A mechanism by which lead may impact dental caries is the theory that lead interferes with the enzymes for extracellular matrix metabolism and the enamel matrix proteinases involved with amelogenesis; however, one study did not show morphological changes associated with blood lead levels in exfoliated primary teeth [Youravong et al., 2005].

Another means by which lead may influence caries development is through interference with salivary function. In a rat model, there was nearly a $40 \%$ increase in caries and a $30 \%$ decrease in stimulated saliva from the parotid with lead exposure [Watson et al., 1997]. Without salivary protection, teeth are more vulnerable to dental caries.

Additionally, lead is thought to bind with fluoride in saliva and reduce the bioavailability of the fluoride for remineralization [Moss et al., 1999]. Recently, Youravong et al. [2013] described the relationship of elevated salivary lead levels and a relationship with decreased Streptococcus mutans carriage, indicating a possible shift in the oral microbiota that may be related to other cariogenic bacteria flourishing. Salivary lead level detection has been problematic due to methodological issues and salivary collection techniques. Variables in circadian effects on salivary flow, stimulated versus unstimulated whole saliva detection methods, lack of documented reference standards, and low levels of lead within the saliva have adversely impacted current information.

The studies involving lead and dental caries have had equivocal results, with Moss et al. [1999] supporting the relationship, Campbell et al. [2000] not demonstrating that an exposure of $>10 \mu \mathrm{g} / \mathrm{dl}$ as a toddler is a predictor of dental caries in school-aged children, Martin et al. [2007] supporting a weak male-only association of lead exposure with primary tooth caries, and Malara et al. [2006] not finding a significant difference in lead concentration and the roots of carious/noncarious permanent teeth. Study designs had the following significant differences: lead levels were determined using log-transformed lead levels or lead levels dichotomized at 5 or $10 \mu \mathrm{g} / \mathrm{dl}$; participants had different age categories in the different studies; caries was evaluated on permanent/mixed/primary dentitions, and caries prevalence as decayed and filled primary teeth (dft, presence/absence) was used as an outcome [Moss et al., 1999; Campbell et al., 2000; Martin et al., 2007]. None of the studies adjusted for zero inflation (the high number of children who had no caries) or the extent/severity of caries using modeling of the mean of the number of decayed/filled teeth in the sample. Also, with the geometric 
mean of blood lead level at $1.9 \mu \mathrm{g} / \mathrm{dl}$ for $1999-2002$ and $1.3 \mu \mathrm{g} / \mathrm{dl}$ for 2007-2010, it may be appropriate to use $2 \mu \mathrm{g} / \mathrm{dl}$ as a reference category in current research [Gilbert and Weiss, 2006].

The aim of this study was to examine the association between caries in children aged 24-72 months and their blood lead levels using a statistical test, zero-inflated negative binomial (ZINB) regression, to determine the relationship. The data to be used are from NHANES III. The hypothesis is that lead is strongly associated with dental caries, and the relationship requires a special analytic technique to properly express that relationship.

\section{Methods}

This study involved secondary data analysis of deidentified public access data and did not require institutional review board approval. The NHANES III study, which provided the data, was conducted by the National Center for Health Statistics (NCHS) of the CDC. The NHANES III received institutional review board approval and documented consent was obtained from participants [NCHS, 2012]. NHANES III was a nationally representative survey with a complex survey design. It consisted of interviews of noninstitutionalized US citizens. The interviews included demographic, socioeconomic, dietary, and health-related questions. The survey also had medical and dental examinations, physiological measurement such as height and weight, and laboratory tests on blood and/or urine. The survey was designed to over-sample certain groups (children aged 2 months to 5 years, adults aged 60 years and above, African-Americans, and Hispanics) to provide more reliable statistics [NCHS, 2012]. Further details of the survey are available on the CDC website [NCHS, 2012]. The entire NHANES III sample (1988-1994) included 33,994 participants. The sample had 10,332 children aged from 2 to 18 years [Vargas et al., 1998].

The sample used in this study included children aged 24-72 months who did not have missing data on blood lead levels, dental examination, sex, race/ethnicity, age, poverty index, urban/nonurban status, family's highest education, smoking in the household, birth weight, having been breast-fed, and last dental visit. The sample consisted of 3,127 participants.

The dental examinations for participants were conducted with front-surface mirrors and No. 23 explorers to evaluate all the teeth present [Vargas et al., 1998]. This study used the results of the examinations of dft on tooth-level data of primary teeth. Teeth which were unerupted or missing due to nondisease were coded as such and not considered in the analysis. The National Institute of Dental Research and a dental consultant trained and calibrated the examiners (NHANES, 1988-1994). One of the examiners conducted nearly $50 \%$ of the examinations; three others and one back-up examiner conducted the remainder of the evaluations [Vargas, 1998]. A 'gold-standard' examiner observed and replicated evaluations on approximately 30 participants once or twice annually; similarly, each examiner replicated evaluations on a sample of participants within the 6-week period/location (NHANES, 1988-1994). Intra- and interexaminer calibrations were satisfactory [Vargas, 1998]. The interrater reliability compared reference and examiner; the interrater reliability resulted from repeated examinations and paired observations were used to calculate Cohen's kappa (0.641.00 for caries) [Beltrán-Aguilar et al., 2005].

\section{Outcome Variable}

The outcome variable was the count of $\mathrm{dft}$ - the number of primary teeth with at least 1 decayed or filled surface.

\section{Main Variable of Interest}

The main variable of interest was the blood lead level. It was categorized as $<2 \mu \mathrm{g} / \mathrm{dl}$ (the reference category), $2-5,5-10$ and $>10$ $\mu \mathrm{g} / \mathrm{dl}$. The children with blood lead levels below the detection limit of $1 \mathrm{ug} / \mathrm{dl}$ (NHANES, 1988-1994) were categorized as $<2 \mu \mathrm{g} / \mathrm{dl}$. NHANES III returned laboratory results below the lower detection limit with a value equal to the detection limit divided by the square root of 2 to distinguish nondetectable laboratory results from detectable results [Vargas et al., 1998].

\section{Other Variables}

Other variables in the analysis included predisposing factors such as sex (male vs. female), age (3, 4 and 5 years vs. 2 years as the reference, having the least accumulated exposure) and race/ethnicity (other, non-Hispanic Black and Mexican-American vs. nonHispanic White as the reference). Enabling factors included in the study were as follows: poverty index (below poverty level vs. at or above poverty level as the reference, having the greater potential to not having been exposed to lead-based paints), urban status (nonurban vs. urban), census region (South, West and Midwest vs. Northeast as the reference, as the West has greater lead deposits, the soil along the lower Mississippi has greater lead content and the Northeast has significant industry), and the highest education level in the family (less than high school and high school graduate vs. more than high school). Lifestyle/behavioral factors included in the study were smoking in the household (yes vs. no as a reference due to the potential of lead exposure from passive smoke), birth weight $(<2,500$ and $>4,100 \mathrm{~g}$ vs. $2,500-4,100 \mathrm{~g}$ as a reference), breast-fed (yes vs. no as the reference), parent/guardian perception of the condition of the child's teeth (very good, good, fair and poor vs. excellent as a reference), and last dental visit (at least one vs. never as the reference).

\section{Statistical Methods}

To account for the NHANES complex survey design, Rao-Scott $\chi^{2}$ tests were used to examine the associations between blood lead levels and predisposing, enabling and lifestyle/behavioral factors in bivariate analysis.

To account for the high number of children who do not have caries [Böhning et al., 1999], zero-inflated regression methods were applied to account for the excess zeroes. Through graphical comparison of Poisson, negative binomial, zero-inflated Poisson, and ZINB models with the observed data, the ZINB model was determined to provide the best model fit (fig. 1). To explore the influence of the other variables on the relationship between blood lead levels and caries severity, an unadjusted ZINB model was fit, as well as a model adjusting for the other variables listed above. Discussions of the mean severity estimation and standard error calculation for zero-inflated models are presented elsewhere [Preisser et al., 2012]. 


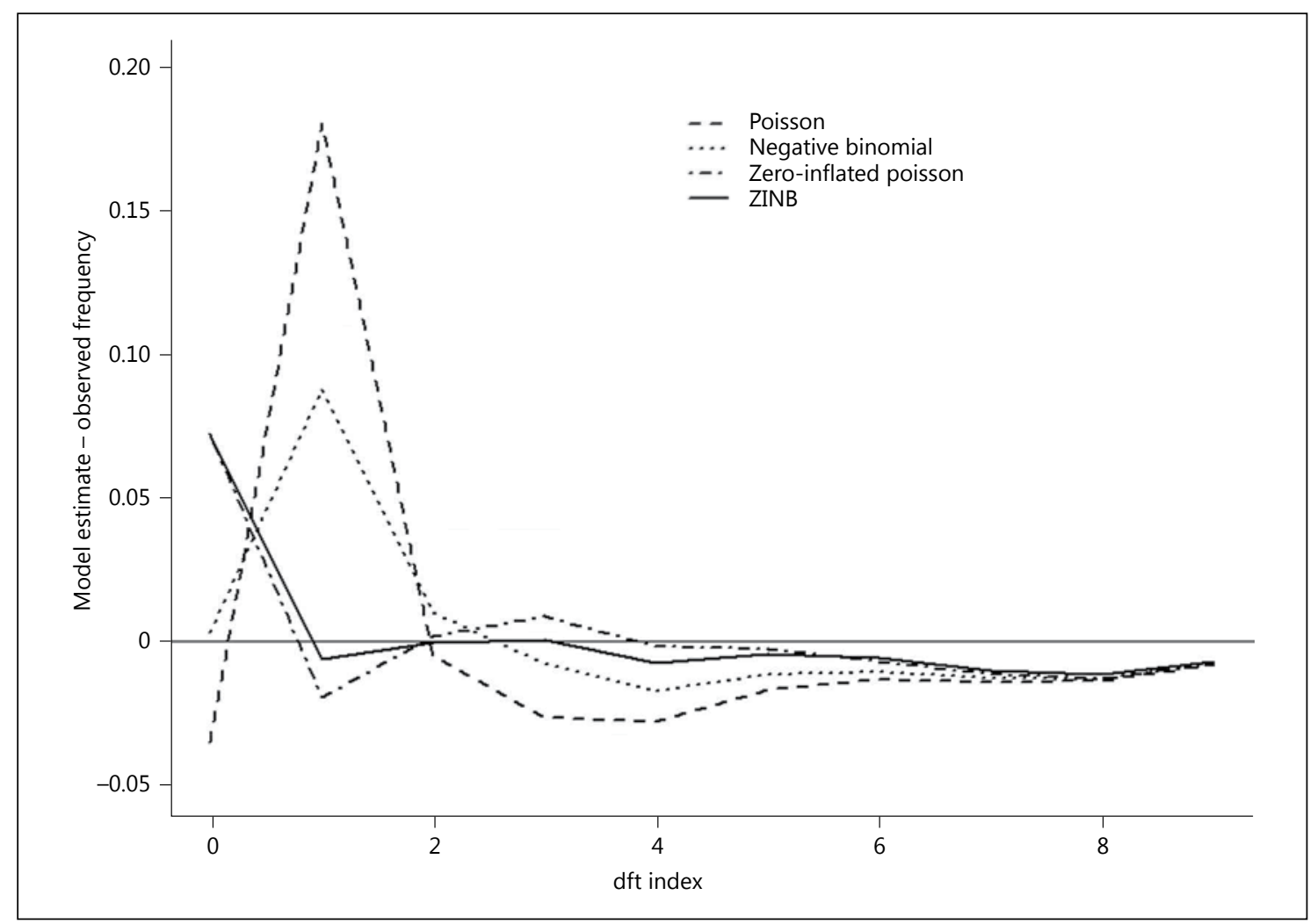

Fig. 1. Differences in model predictions and observed frequencies for examination of model selection between 4 possible model choices (Poisson, negative binomial, zero-inflated Poisson and ZINB).

SAS version 9.3 (SAS Institute Inc., Cary, N.C., USA) was used for all descriptive statistics and mean severity ratio calculations. Additionally, STATA 12.1 (StataCorp LP, College Station, Tex., USA) was used to apply the ZINB models, with special consideration given to the complex multistage sampling scheme of NHANES III. Software code and necessary ZINB model information for the mean severity calculations are provided in the online supplementary material (for all online suppl. material, see www. karger.com/doi/10.1159/000365297).

\section{Results}

There were 3,127 participants. The survey-weighted mean number of teeth with caries/restorations was 1.03 (standard error 0.09). In this sample, approximately $76 \%$ of the children had no caries, $13 \%$ had $1-3 \mathrm{dft}$ and $11 \%$ had $>3 \mathrm{dft}$.

Table 1 has data on the sample characteristics. The sample was $51.90 \%$ male and $62.54 \%$ non-Hispanic White. The families were generally above the poverty line $(70.56 \%)$, had at least 1 member who was at or above a high school education (74.84\%) and did not have smoking in the household (62.03\%); $8.5 \%$ of the children had a birth weight $<2,500 \mathrm{~g}$. The children were evenly distributed in age (2-5 years), urban/nonurban status, having been breast-fed, and having had a dental visit. The blood lead levels were $<2 \mu \mathrm{g} / \mathrm{dl}$ for $28.19 \%$ of the participants and between 2 and $5 \mu \mathrm{g} / \mathrm{dl}$ for $48.29 \%$ of the participants.

Table 2 has the predisposing, enabling and lifestyle/ behavioral variables by the exposure of interest (blood lead level categories). There were significant associations between higher blood lead levels and age, race/ethnicity, census region, living below the poverty level, living in a household where the highest education was less than a high school education, living in a household where smoking occurred, low birth weight, reported condition of teeth, and dental visit. The associated weighted percentages of $>10 \mu \mathrm{g} / \mathrm{dl}$ were $45.10 \%$ (for non-Hispanic Blacks), $62.69 \%$ (for living under the poverty level), 51.79\% (for living in a household where the highest education was less than a high school education), $74.96 \%$ (for bottle-feed- 
ing), and $54.71 \%$ (for living in a household where someone smoked).

Table 3 has the overall mean severity ratios from both the unadjusted and adjusted ZINB models. For the blood lead group of 5-10 $\mu \mathrm{g} / \mathrm{dl}$, the overall adjusted mean severity ratio was 2.138 , indicating that children in this blood lead group had $113.8 \%$ more caries on average than children with a blood lead level of $<2 \mu \mathrm{g} / \mathrm{dl}$. The adjusted mean severity ratios were 1.840, 2.138 and 1.906, respectively, for the categories of 2-5, 5-10 and $>10 \mu \mathrm{g} /$ $\mathrm{dl}$ for $\mathrm{dft}$ compared with children with blood lead levels $<2 \mu \mathrm{g} / \mathrm{dl}$, adjusting for sex, race/ethnicity, age, urban status, census region, poverty level, highest household education, smoking in the household, birth weight, whether the child was breast-fed, and whether the child visited the dentist.

\section{Discussion}

The results of this study indicate a strong independent association of lead with the severity/extent of caries in children aged 24-72 months using a statistical technique to account for the inflation of values due to the high number of children with no caries. The unadjusted severity/extent mean ratio for children with $>10 \mu \mathrm{g} / \mathrm{dl}$ was 1.937 , and the adjusted value was 1.906 . Among the blood lead groups of $2-5$ and $5-10 \mu \mathrm{g} / \mathrm{dl}$, the relationship was strengthened by adjusting for the other variables. This strengthening of association was not observed in the highest exposure group, although the effect remained significant. The survey-weighted mean number of teeth with caries/restorations was 1.03 (standard deviation 0.09 ), with approximately $76 \%$ of children having no caries.

This is the first study to examine the severity/extent mean ratio between lead and caries using transformations of zero-inflated modeling techniques to obtain overall effect estimates of blood lead exposure on caries severity. One of its strengths is that it was from a large, national survey in which calibrated investigators used validated and reliable questionnaires. Oral evaluations for $\mathrm{dft}$ and laboratory procedures for blood lead levels were also calibrated. A limitation of the study, and any study using a cross-sectional study design, is that temporality is a concern. This study supports a previous study of NHANES III data which examined the prevalence of caries in children aged 2 years through to 12 years and found an association of decayed, missing and filled surfaces in primary and permanent teeth [Moss et al., 1999]. Other studies of
Table 1. Description of NHANES III subsample characteristics $(\mathrm{n}=3,127)$

\begin{tabular}{|c|c|c|}
\hline & Number & Weighted \% \\
\hline \multicolumn{3}{|l|}{ Blood lead levels, $\mu \mathrm{g} / \mathrm{dl}$} \\
\hline$<2$ & 594 & 28.19 \\
\hline $2-5$ & 1,500 & 48.29 \\
\hline $5-10$ & 785 & 18.44 \\
\hline$>10$ & 248 & 5.08 \\
\hline \multicolumn{3}{|l|}{ Sex } \\
\hline Female & 1,561 & 48.10 \\
\hline Male & 1,566 & 51.90 \\
\hline \multicolumn{3}{|l|}{ Race/ethnicity } \\
\hline Non-Hispanic White & 897 & 62.54 \\
\hline Non-Hispanic Black & 1,017 & 16.47 \\
\hline Mexican-American & 1,048 & 9.76 \\
\hline Other & 165 & 11.23 \\
\hline \multicolumn{3}{|l|}{ Age, years } \\
\hline 2 & 795 & 23.52 \\
\hline 3 & 762 & 24.86 \\
\hline 4 & 801 & 24.39 \\
\hline 5 & 769 & 27.23 \\
\hline \multicolumn{3}{|l|}{ Poverty index } \\
\hline Below poverty & 1,338 & 29.44 \\
\hline At or above poverty & 1,789 & 70.56 \\
\hline \multicolumn{3}{|l|}{ Urban } \\
\hline Urban & 1,611 & 47.83 \\
\hline Nonurban & 1,516 & 52.17 \\
\hline \multicolumn{3}{|l|}{ Census region } \\
\hline Northeast & 322 & 15.97 \\
\hline Midwest & 548 & 23.16 \\
\hline South & 1,400 & 35.79 \\
\hline West & 857 & 25.08 \\
\hline \multicolumn{3}{|c|}{ Highest education in household } \\
\hline Less than high school & 1,160 & 25.16 \\
\hline High school graduate & 1,032 & 33.35 \\
\hline More than high school & 935 & 41.49 \\
\hline \multicolumn{3}{|l|}{ Smoking in household } \\
\hline Yes & 1,164 & 37.97 \\
\hline No & 1,963 & 62.03 \\
\hline \multicolumn{3}{|l|}{ Birth weight, $g$} \\
\hline$<2,500$ & 283 & 8.53 \\
\hline $2,500-4,100$ & 2,621 & 83.08 \\
\hline$>4,100$ & 223 & 8.39 \\
\hline \multicolumn{3}{|l|}{ Breast-fed } \\
\hline Yes & 1,383 & 53.85 \\
\hline No & 1,744 & 46.15 \\
\hline \multicolumn{3}{|c|}{$\begin{array}{l}\text { Parent/guardian perception of the } \\
\text { condition of the child's teeth }\end{array}$} \\
\hline Excellent & 1,041 & 40.12 \\
\hline Very good & 690 & 23.37 \\
\hline Good & 913 & 25.49 \\
\hline Fair & 313 & 7.12 \\
\hline Poor & 170 & 3.90 \\
\hline \multicolumn{3}{|l|}{ Last visit to dentist } \\
\hline Never & 1,837 & 53.06 \\
\hline At least once & 1,290 & 46.94 \\
\hline
\end{tabular}


Table 2. Blood lead levels and variables of interest: NHANES III

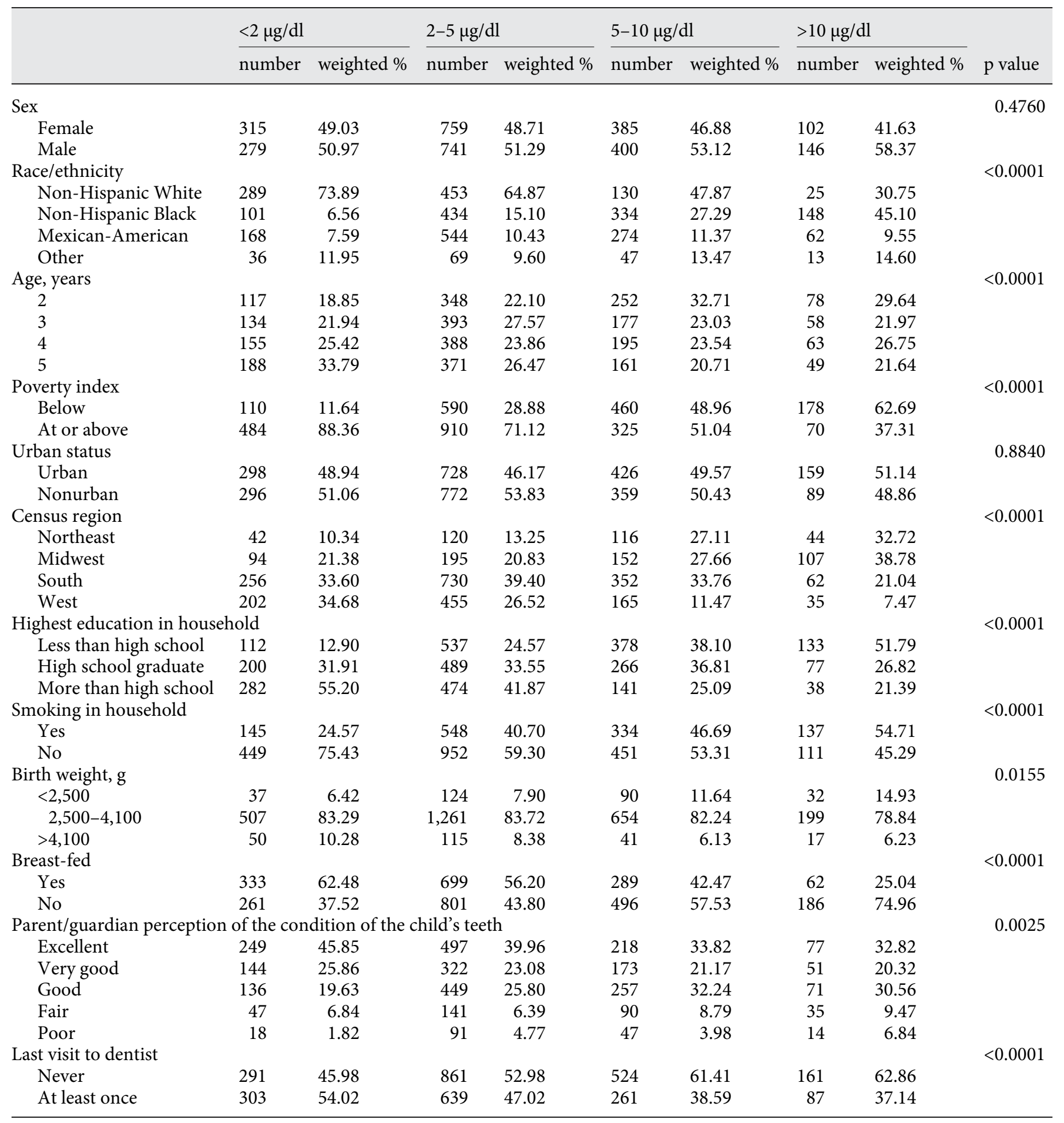

Weighted percentages were obtained to control for complex sample design, therefore the division of individual cell sizes by the total sample will not reflect weighted percentages. Significant group differences were tested by $\chi^{2}$ statistics. 
Table 3. Overall mean severity ratio estimates for $\mathrm{dft}$ count in children aged 24-72 months: NHANES III $(\mathrm{n}=3,127)$

\begin{tabular}{|c|c|c|}
\hline Variables & Unadjusted & Adjusted $^{1}$ \\
\hline \multicolumn{3}{|l|}{ Blood lead levels, $\mu \mathrm{g} / \mathrm{dl}$} \\
\hline$<2$ & 1.000 & 1.000 \\
\hline $2-5$ & $1.788(1.191-2.685)$ & $1.840(1.355-2.499)$ \\
\hline $5-10$ & $1.878(1.249-2.822)$ & $2.138(1.363-3.355)$ \\
\hline$>10$ & $1.937(1.186-3.165)$ & $1.906(1.170-3.106)$ \\
\hline \multicolumn{3}{|l|}{ Sex } \\
\hline Female & & 1.000 \\
\hline Male & & $0.848(0.678-1.059)$ \\
\hline \multicolumn{3}{|l|}{ Race/ethnicity } \\
\hline White & & 1.000 \\
\hline Black & & $1.451(0.977-2.156)$ \\
\hline Mexican-American & & $1.975(1.382-2.824)$ \\
\hline Other & & $2.528(1.349-4.739)$ \\
\hline \multicolumn{3}{|l|}{ Age, years } \\
\hline 2 & & 1.000 \\
\hline 3 & & $3.441(1.921-6.162)$ \\
\hline 4 & & $4.875(2.794-8.506)$ \\
\hline 5 & & $8.633(5.294-14.078)$ \\
\hline \multicolumn{3}{|l|}{ Urban status } \\
\hline Urban & & 1.000 \\
\hline Nonurban & & $1.384(1.043-1.836)$ \\
\hline \multicolumn{3}{|l|}{ Census region } \\
\hline Northeast & & 1.000 \\
\hline South & & $1.045(0.605-1.805)$ \\
\hline West & & $1.337(0.785-2.276)$ \\
\hline Midwest & & $1.216(0.698-2.120)$ \\
\hline \multicolumn{3}{|l|}{ Poverty index } \\
\hline \multicolumn{3}{|l|}{ At or above } \\
\hline poverty level & & 1.000 \\
\hline \multicolumn{3}{|l|}{ Below poverty } \\
\hline level & & $1.119(0.788-1.589)$ \\
\hline \multicolumn{3}{|c|}{ Highest family education level } \\
\hline \multicolumn{3}{|l|}{ Less than } \\
\hline high school & & $0.957(0.581-1.576)$ \\
\hline High school & & 1.000 \\
\hline \multicolumn{3}{|l|}{ More than } \\
\hline high school & & $0.920(0.587-1.443)$ \\
\hline \multicolumn{3}{|l|}{ Smoking in household } \\
\hline No & & 1.000 \\
\hline Yes & & $1.818(1.406-2.349)$ \\
\hline \multicolumn{3}{|l|}{ Birth weight, g } \\
\hline$<2,500$ & & $0.752(0.394-1.435)$ \\
\hline $2,500-4,100$ & & 1.000 \\
\hline 4,100 & & $0.793(0.441-1.425)$ \\
\hline \multicolumn{3}{|l|}{ Breast-fed } \\
\hline No & & 1.000 \\
\hline Yes & & $1.130(0.851-1.500)$ \\
\hline \multicolumn{3}{|l|}{ Dental visit } \\
\hline No & & 1.000 \\
\hline Yes & & $1.559(1.104-2.201)$ \\
\hline \multicolumn{3}{|c|}{ Parental perception of oral health } \\
\hline Excellent & & 1.000 \\
\hline Very good/good & & $4.182(2.650-6.599)$ \\
\hline Fair/poor & & $25.864(16.863-39.668)$ \\
\hline
\end{tabular}

Values in parentheses are $95 \%$ confidence intervals.

${ }^{1}$ Mean severity ratios are estimated from ZINB regression with all covariates in each part of the model, using survey-weighted mean levels of all other variables. caries and lead exposure involved older children. One study indicated that urban children aged 6-10 years with increased blood lead levels had an association with caries; another study indicated a relationship of blood lead level and caries only with males, and only in primary teeth, and another indicated no increased association of decayed, filled and missing teeth with blood lead levels early in life (18-37 months) [Bellinger, 2011]. This study adds to the literature a strong association between lead exposure and severity/extent of caries in children aged 24-72 months. Even observed differences between $<2$ and $2-5 \mu \mathrm{g} / \mathrm{dl}$ indicate support for lower limits of risk with lower exposure.

Future research is needed into the development of a quick salivary lead detection test [Youravong et al., 2013] which could be used by dentists in the routine care of children to determine high lead exposures, refer for followup care and use to inform caries risk assessment. Caries progression is a concern and dentists need to be aware of factors beyond the traditional risk factors for early childhood caries and to consider those risks in caries risk assessments. Future research is also needed to investigate lead exposure to specific populations. Children immigrating to the USA from China, where rice contamination with lead is high, may be at increased risk of lead poisoning and associated caries. Children emigrating from emerging market countries may be at greater risk of exposure to lead from industrial emissions, fossil fuel burning, waste incineration, consumer products, mining, and smelting due to limited regulatory oversight [Horton et al., 2013]. There is a high caries incidence in Native American children. Do these children have a higher lead exposure? The current research sample was not powered to evaluate subpopulations. Most of the lead exposure in the USA is from pockets of low-income, urban neighborhoods with older housing [Horton et al., 2013]. Policy research is also needed to determine a means of lead abatement in housing in which lead paint was not removed or contained after the 1978 federal ban on lead paint [Korfmacher and Hanley, 2013]. The researchers for the CDC state that primary prevention, the assurance that all homes are lead-safe, is the only practical approach to preventing elevated blood lead levels, and prevention policies should be targeted at the children most at risk [Wheeler and Brown, 2013].

Despite considerable efforts, the problem of lead has not disappeared, and the threshold level of safety has not been determined [Bellinger, 2011]. This study indicates that even low blood lead levels are associated with increased dental caries extent/severity in early life. 


\section{Acknowledgment}

The research reported in this publication was supported by the National Institute of General Medical Sciences of the National Institutes of Health (Award No. U54GM104942). The content is solely the responsibility of the authors and does not necessarily represent the official views of the National Institutes of Health. The funders had no role in the study design, data collection and analysis, decision to publish, or preparation of the manuscript. R.C.W. and D.L.L. conceived and designed the study; R.C.W. and R.J.J. conducted the literature search; D.L.L. analyzed the data, and R.C.W., R.J.J. and D.L.L. wrote the paper.

\section{Disclosure Statement}

The authors have no conflicts of interests to declare.

\section{References}

Alomary A, Al-Momani IF, Obeidat SM, Massadeh AM: Levels of lead, cadmium, copper, iron, and zinc in deciduous teeth of children living in Irbid, Jordan by ICP-OES: some factors affecting their concentrations. Environ Monit Assess 2013;185:3283-3295.

Bellinger DC: Protean toxicities of lead: new chapters in a familiar story. Int J Environ Res Pub Health 2011;8:2593-2628.

- Beltrán-Aguilar ED, Barker LK, Canto MT, Dye BA, Gooch BF, Griffin SO, Hyman J, Jaramillo F, Kingman A, Nowjack-Raymer R, Selwitz RH, Wu W: Surveillance for dental caries, dental sealants, tooth retention, edentulism, and enamel fluorosis - United States, 1988-1994 and 1999-2002. MMWR Surveill Summ 2005;54:1-44.

-Böhning D, Dietz E, Schlattmann P, Medonça V, Kirchner U: The zero-inflated Poisson model and decayed, missing and filled teeth index in dental epidemiology. J R Stat Soc Ser A Stat Soc 1999;162:195-209.

Campbell JR, Moss ME, Raubertas RF: The association between caries and childhood lead exposure. Environ Health Perspect 2000;108: 1099-1102.

CDC: Managing Elevated Blood Lead Levels among Young Children: Recommendations from the Advisory Committee on Childhood Lead Poisoning Prevention. Centers for Disease Control and Prevention, 2009, updated. http://www. cdc.gov/nceh/lead/CaseManagement/ caseManage_chap2.htm\#Effectiveness.

CDC: Lead Recalls: Toys. Centers for Disease Control and Prevention, 2012, updated. http://www.cdc.gov/nceh/lead/Recalls/toys. htm.

Gierat-Kucharzewska B, Braziewicz J, Majewska U, Gozdz S, Karasinski A: Concentration of selected elements in the roots and crowns of both primary and permanent teeth with caries disease. Biol Trace Elem Res 2003;96:159-167.
Gilbert SG, Weiss B: A rationale for lowering the blood lead level from 10 to $2 \mu \mathrm{g} / \mathrm{dl}$. Neurotoxicology 2006;27:693-701.

Horton LM, Mortensen ME, Iossifova Y, Wald MM, Burgess P: What do we know of childhood exposures to metals (arsenic, cadmium, lead, and mercury) in emerging market countries. Int J Pediatr 2013;2013:872596.

Jaslow R: Imported Rice May Contain Dangerously High Lead Levels. CBS News, April 11, 2013, 11:18 a.m. http://www.cbsnews.com/8301204_162-57579062/imported-rice-maycontain-dangerously-high-lead-levels/.

Korfmacher KS, Hanley ML: Are local laws the key to ending childhood lead poisoning? J Health Polit Policy Law 2013;38:757-813.

- Malara P, Kwapulinski J, Malara B: Do the levels of selected metals differ significantly between the roots of carious and non-carious teeth? Sci Total Environ 2006;369:59-68.

Martin MD, Benton T, Bernardo M, Woods JS, Townes BD, Luis H, Letao J, Rosenbaum G, Castro-Caldas A, Pavao I, Rue T, DeRouen TA: The association of dental caries with blood lead in children when adjusted for IQ and neurobehavioral performance. Sci Total Environ 2007;377:159-164.

Moss ME, Lanphear BP, Auinger P: Association of dental caries and blood lead levels. JAMA 1999;281:2294-2298.

NCHS: National Center for Health Statistics Research Ethics Review Board (ERB) Approval Centers for Disease Control and Prevention, 2012, updated. http://www.cdc.gov/nchs/ nhanes/irba98.htm.

- Preisser JS, Stamm JW, Long DL, Kincade ME: Review and recommendations for zero-inflated count regression modeling of dental caries indices in epidemiological studies. Caries Res 2012;46:413-423.
Rosin A: The Long-term consequences of exposure to lead. Isr Med Assoc J 2009;11:689694.

Third National Health and Nutrition Examination Survey (NHANES III), 1988-94 Catalog No 76200, NHANES III Examination Data File Documentation: ages two months and older. ftp://ftp.cdc.gov/pub/Health_Statistics/ NCHS/nhanes/nhanes3/1A/exam-acc.pdf.

Third National Health and Nutrition Examination Survey (NHANES III), 1988-94 Catalog No 76300, NHANES III Laboratory Data File Documentation. ftp://ftp.cdc.gov/pub/ Health_Statistics/NCHS/nhanes/nhanes3/ 1A/lab-acc.pdf.

-Vargas CM, Crall JJ, Schneider DA: Sociodemographic distribution of pediatric dental caries: NHANES III, 1988-1994. J Am Dent Assoc 1998;129:1229-1238.

-Watson GE, Davis BA, Raubertas RF, Pearson SK, Bowen WH: Influence of maternal lead ingestion in rat pups. Nat Med 1997;3:1024-1025.

Wheeler W, Brown MJ: (Reported by) Blood lead levels in children aged 1-5 years - United States, 1999-2010. MMWR Morb Mort Wkly Rep 2013;62:245-248.

-Youravong N, Chongsuivalwong V, Geater AF, Dahlen G, Teanpaisan R: Lead-associated caries development in children living in a lead contaminated area, Thailand. Sci Total Environ 2006;361:88-96.

Youravong N, Chongsuvivatwong V, Teanpaisan R, Geater AF, Dietz W, Dahlen G, Noren JG: Morphology of enamel in primary teeth from children in Thailand exposed to environmental lead. Sci Total Environ 2005;348:7381.

Youravong N, Teanpaisan R, Chongsuvivatwong $\mathrm{V}$ : Salivary lead in relation to caries, salivary factors and cariogenic bacteria in children. Int Dent J 2013;63:123-129. 